\title{
Bone demineralisation in patients with Turner's syndrome
}

\author{
M A SMITH, * J WILSON, $\uparrow$ AND W H PRICE $\dagger$ \\ From * the Department of Medical Physics and Medical Engineering, The Royal Infirmary, Edinburgh, and \\ $\dagger M R C$ Clinical and Population Cytogenetics Unit and University Department of Medicine, \\ Western General Hospital, Edinburgh
}

SUMMARY The hypothesis that the demineralisation associated with gonadal dysgenesis is analogous to post-menopausal osteoporosis was investigated. Bone mineral content of the distal forearm was measured in 11 adult patients with Turner's syndrome aged 18 to 57 years. As a group these patients were significantly demineralised $(\mathrm{p}<0.001)$ when compared with normal subjects. A bimodal $\odot$ distribution of bone mineral was demonstrated, the eight patients below the normal range having a $\frac{\text { ? }}{2}$ bone mineral content $73 \%$ of normal. This may be the usual bone mineral content for a large proportion of Turner's patients. No steady reduction in mineralisation with age was demonstrated. The number of osteoporotic type fractures was obtained from the records of 36 adult patients with Turner's syndrome. From the cumulative total years at risk ( 770 patient years) from the age of 15 years, it was found that the number of fractures of the distal radius corresponded to the normal premenopausal rather than post-menopausal fracture incidence. The absence of any reduction in bone mineral content with age and no clear evidence of an increase in frequency of fractures both suggest that the demineralisation associated with Turner's syndrome is not analogous to post-menopausal osteoporosis. The regular use of long term oestrogen therapy as a treatment for 'osteoporosis' in these patients is therefore not justified.

Qualitative assessment of skeletal radiographs from patients with Turner's syndrome has demonstrated that in this condition osteoporosis occurs with a frequency of between 60 and $80 \% \%^{1-4}$ In affected children bone histology has shown increased bone resorption with normal bone formation, ${ }^{5}$ while radiographs of the second metacarpals show reduced total diameters and increased medullary diameters. ${ }^{26}$

The degree of demineralisation owing to osteoporosis can be assessed quantitatively using the technique of photon absorptiometry. The linear density of bone is obtained from the degree of attenuation of radiation from a monoenergetic radionuclide source. ${ }^{7}$ This technique has been used to demonstrate demineralisation of the radius and os calcis in children and young adults. ${ }^{5} 8$

Oestrogen inhibits bone resorption in osteoporosis ${ }^{9}$ and has been advocated for the treatment of post-menopausal osteoporosis. ${ }^{10}$ The rationale behind this treatment is the prevention of the normal loss of bone mineral of about $1 \%$ per annum, ${ }^{11}$ thus reducing the likelihood of debilitating fractures in later life. There are, however, disadvantages since Received for publication 11 May 1981. there is evidence that when it is terminated the mineral content falls to the level at which it would have been had no treatment been given. ${ }^{12}$ Thus, to achieve a long term benefit, oestrogen therapy may have to be continuous. Other disadvantages include associated side effects such as increased incidences of abnormal uterine bleeding and endometrial carcinoma. ${ }^{13-16}$

The treatment of osteoporosis in patients with $\mathrm{O}$ Turner's syndrome might depend on whether osteoporosis associated with gonadal dysgenesis is analogous to post-menopausal osteoporosis in normal women. If it is, there should be a steady of decrease in bone mineral after the age of about $15 \mathrm{~N}$ years combined with a raised incidence of fractures. In these circumstances long term oestrogen therapy would be indicated.

The present study was undertaken to investigate the bone mineral content (BMC) in adult patients with Turner's syndrome, and to assess the severity and age relationship of any deficit in bone mineralisation. The incidence of osteoporotic fractures has also been examined and compared with the incidence in the general population. 


\section{Patients and methods}

The bone mineral content was studied in 11 adult patients with Turner's syndrome over a wide age range (18 to 57 years). These were available patients with Turner's syndrome in the south-east of Scotland who were over the age of 18 years and who had been registered with the MRC Cytogenetics Unit. They had all given informed consent to the investigation. Their mean height was $140 \cdot 8 \mathrm{~cm}$. Other details of the patients are given in table 1. For comparison we studied a group of 16 healthy premenopausal women of presumed normal karyotype aged 18 to 44 years. Within the group of 16 there was a subgroup of 11 short women with a mean height of $154.0 \mathrm{~cm}$ whose BMC measurements were used to establish the normal range. The remaining five were significantly taller with a mean height of $169 \cdot 1 \mathrm{~cm}$, and their BMC measurements were used to determine the effect of a height difference of $15 \mathrm{~cm}$.

The BMC of the non-dominant forearm was measured by photon absorptiometry using a commercial 'Novo Osteodensitometer' which had a reproducibility of $1.4 \%{ }^{17}$ The source and detector scan the forearm in a rectilinear motion from the distal end. The BMC is measured for each traverse, but is only stored once the gap between the radius and ulna exceeds $6 \mathrm{~mm}$. A further five scans, $4 \mathrm{~mm}$ apart, are performed and the total BMC of the radius and ulna are recorded. The width of the radius and the ulna on the third and sixth traverse were measured from a chart recorder output and their sum total (W) used as a normalisation factor.

The medical records of the 11 patients with Turner's syndrome and of 25 others with the same diagnosis were examined. Their mean age was $36 \cdot 4 \pm 8 \cdot 4$ years $( \pm \mathrm{SD})$. The number of fractures since the age of 15 years of the type associated with osteoporosis, that is, of the distal radius and of the neck of the femur, was noted and compared with figures for a normal Scottish population. ${ }^{18}$ The cumulative total years at risk in the group of 36

TABLE 1 Details of patients with Turner's syndrome on whom the BMC of the distal forearm was measured

\begin{tabular}{llll}
\hline Patient & Age & Karyotype & Oestrogen therapy \\
\hline ES & 18 & $45, X / 46, X i(X q)$ & $1978-$ \\
JC & 26 & $45, X / 46, X Y$ & Never \\
CM & 26 & $45, X$ & Never \\
MV & 27 & $45, X$ & $1972-1973$ \\
IC & 35 & $45, X$ & $1965-1977$ \\
SG & 36 & $45, X / 46, X Y$ & $1964-1965$ \\
HB & 39 & $46, X i(X q)$ & $1974-$ \\
MS & 42 & $45, X$ & $1956-1967$ \\
FS & 47 & $45, X$ & $1956-1961$ \\
ML & 45 & $45, X$ & Irregularly until 1977 \\
HS & 57 & $45, X$ & Never \\
\hline
\end{tabular}

patients with Turner's syndrome was 770 patient years.

\section{Results}

The results of BMC measurements are displayed in fig 1. For three patients with Turrer's syndrome they were within the normal range and for eight they were significantly low (five patients $p<0.05$, three patients $p<0.01$ ). The mean for the group of patients with Turner's syndrome was $2 \cdot 31 \pm 0 \cdot 44$ (arbitrary units \pm SD) which is significantly lower $(\mathrm{p}<0.01)$ than for the group of normal subjects, whose mean was $2 \cdot 85 \pm 0 \cdot 27$. The results of the group of taller normals (mean $\mathrm{BMC}=2.94$ ) demonstrated that a height difference of $15 \mathrm{~cm}$ did not significantly affect the normalised BMC values. It can be seen in fig 1 that the eight patients with values outside the normal range are perhaps a subgroup in themselves with a mean value of $2 \cdot 07 \pm 0 \cdot 15$ which is $73 \%$ of normal. Indeed, the three patients (CM, SG, MS) in the normal range were found to be biochemically hypothyroid, a condition which may be expected to increase bone mineral. One of these three patients (SG aged 36) was still menstruating spontaneously.

The values of BMC are plotted against age in

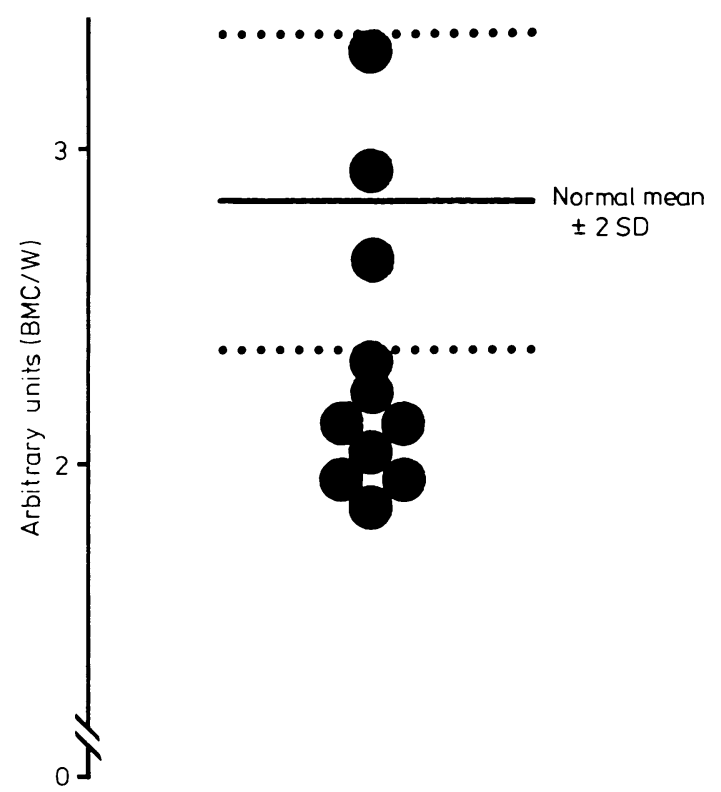

FIG 1 BMC values in patients with Turner's syndrome compared with the normal range. Note the narrow spread in BMC values of patients below the normal range. 


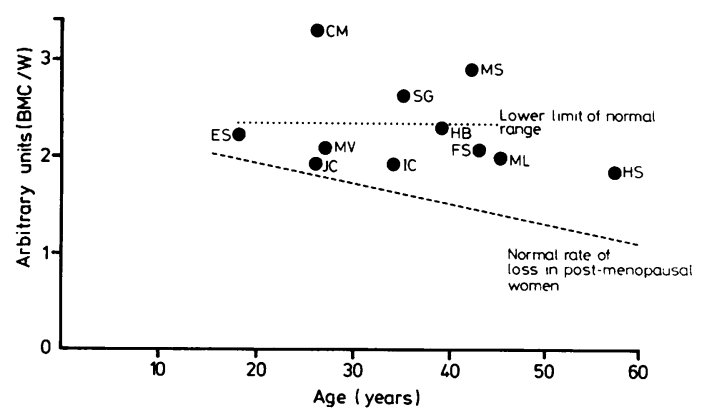

FIG $2 B M C$ values in patients with Turner's syndrome plotted against age. The normal rate of loss in postmenopausal women is shown.

fig 2. No significant correlation was found whether or not patients CM, SG, and MS were included in the analysis. It is apparent from fig 2 that there is no reduction in mineralisation with age as has been found in normal post-menopausal women. The dotted line in fig 2 corresponds to a loss of $1 \%$ per annum, the value obtained by BMC in postmenopausal women, ${ }^{11}$ starting at the age of 15 years and with the BMC equal to the value for the subgroup of eight patients with reduced mineralisation.

There were only two osteoporotic type fractures in the group of 36 Turner patients. One patient had fractured the neck of the femur aged 32 years, and the other the distal radius aged 35 years. The incidence of fractures of the distal radius in the normal population is $0.55 \%$ per annum and $0.15 \%$ per annum for post-menopausal and premenopausal women, respectively. ${ }^{18}$ Applying these values to the accumulated Turner patient years at risk, the expected number of fractures of the distal radius would be four at the post-menopausal fracture rate and one at the premenopausal rate. Similar analysis of neck of femur fractures could not be performed because the number of fractures based on the normal incidences was less than one for both pre- and postmenopausal periods. The patient with a fracture of the lower end of the radius (MS) had a normal BMC.

\section{Discussion}

The results are in good agreement with those obtained in another two studies of bone mineral content in Turner's syndrome. ${ }^{58}$ In both these studies the mean BMC was significantly reduced and in both the values fell into two clear groups, those in the normal range and those which were distinctly low. All three studies therefore suggest a bimodal distribution with the mean for the lower
TABLE 2 Comparison of all quantitative studies of BMC in Turner's patients. Note the close agreement in the results of the three studies.

\begin{tabular}{|c|c|c|c|c|c|}
\hline $\begin{array}{l}B M C \\
\text { site }\end{array}$ & $\begin{array}{l}\text { No } \\
\text { of } \\
\text { patients }\end{array}$ & $\begin{array}{l}\text { Age } \\
\text { range } \\
(y r)\end{array}$ & $\begin{array}{l}\text { No } \\
\text { significantly } \\
\text { demineralised }\end{array}$ & $\begin{array}{l}\text { Mea } \\
\text { demi } \\
(\% o\end{array}$ & $\begin{array}{l}\text { BMC of } \\
\text { eralised patients } \\
\text { normal) }\end{array}$ \\
\hline $\begin{array}{l}\text { Radius } \\
\text { Os calcis } \\
\text { Distal } \\
\quad \text { forearm }\end{array}$ & $\begin{array}{r}8 \\
6 \\
11\end{array}$ & $\begin{array}{r}9-19 \\
17-28 \\
18-57\end{array}$ & $\begin{array}{l}6 \\
3 \\
8\end{array}$ & $\begin{array}{l}71 \% \\
72 \% \\
73 \%\end{array}$ & $\begin{array}{l}\text { Brown et al } 5 \\
\text { Risch et al }{ }^{8} \\
\text { Present study }\end{array}$ \\
\hline
\end{tabular}

values being in close agreement in the three studies (table 2). This suggests that this may be the usual bone mineral content for the larger proportion of Turner patients. The proportion of patients with low values $(73 \%)$ also agrees with the prevalence of 'osteoporosis' found radiologically. ${ }^{1-4}$ The BMC values of the patients bore little or no relationship to whether oestrogen therapy had been administered previously (table 1). This was not surprising as it is known that any gain in bone mineral because of oestrogen therapy disappears once treatment is stopped, ${ }^{12}$ and only two of the patients in this present study are currently receiving oestrogen (ES and HB). The values for both these patients are at the upper end of the range for the sub-group with low BMC values.

The failure to demonstrate a reduction in bone mineral content with age (fig 2) in this study is substantiated by measurements of metacarpal cortical thicknesses in 22 patients aged 18 to 56 years. ${ }^{2}$ No reduction in cortical thickness in the older patients was observed although it was not commented on in the paper. This is contrary to the findings in post-menopausal women in whom there is a progressive reduction in BMC with age. If BMC had been reduced by $1 \%$ per annum in the patients with Turner's syndrome we would have expected to see it even with the relatively small numbers studied.

It had not been our clinical impression that the fracture rate in Turner patients was noticeably different from normal subjects of similar age. Unfortunately, it is not possible to draw firm conclusions from the analysis of fractures in this study because of the small numbers. However, the incidence of fractures of the distal radius does appear to be lower than the incidence in postmenopausal women and is comparable, in fact, to the incidence in women of similar age. A lower than expected fracture rate was also noted by Preger et $a l^{2}$ in a group of over 50 Turner patients.

In conclusion, this study quantifies the bone mineral content in patients with Turner's syndrome. The absence of any reduction in BMC with age and no clear evidence of an increase in frequency of fractures both suggest that if osteoporosis is a 
complication of Turner's syndrome it should not be thought analogous to the osteoporosis that occurs in post-menopausal women. It would not, therefore, be possible to justify the regular use of long term oestrogen therapy in patients with Turner's syndrome on the grounds of 'osteoporosis'.

We wish to thank Novo Diagnostic Systems for the loan of the Osteodensitometer, Mrs D McKinna for secretarial services, and Miss D Lytton of the Department of Medical Illustration.

\section{References}

1 Finby N, Archibald RM. Skeletal abnormalities associated with gonadal dysgenesis. AJR 1963;89:1222-35.

2 Preger L, Steinbach HL, Moskowitz P, Scully AL, Goldberg MB. Roentgenographic abnormalities in phenotypic females with gonadal dysgenesis. $A J R$ 1968;104:899-910.

3 Müller G, Gschwend N. Endokrine störungen und morbus Scheuermann. Arch Orthop Unfallchir 1969;65: 357-62.

4 Beals RK. Orthopaedic aspects of the XO (Turner's syndrome). Clin Orthop 1973;97:19-30.

5 Brown DM, Jowsey J, Bradford DS. Osteoporosis in ovarian dysgenesis. J Pediatr 1974;84:816-20.

6 Garn SM, Poznanski AK, Nagy JM. Bone measurement in the differential diagnosis of osteoporosis and osteopenia. Radiology 1971;100:509-18.

7 Cameron JR, Sorenson J. Measurement of bone mineral in vivo: an improved method. Science 1963;142:230-2.

8 Risch WD, Banzer DH, Moltz L, Schneider U, Rudloff R.
Bone mineral content in patients with gonadal dysfunction. $A J R$ 1976;126:1302.

9 Riggs BL, Jowsey J, Kelly PJ, Jones JD, Maher FT. Effect of sex hormones on bone in primary osteoporosis. $J$ Clin Invest 1969;48:1065-72.

10 Nordin BEC, Horsman A, Crilly RG, Marshall DH, Simpson M. Treatment of spinal osteoporosis in postmenopausal women. $\mathrm{Br} \mathrm{Med} J$ 1980;i:451-4.

11 Mazess RB, Cameron JR. Bone mineral content in normal US whites. International Conference on Bone Mineral Measurement (NIH) 75-683, 1974:228-38.

12 Lindsay R, Hart DM, MacLean A, Clark AC, Kraszewski A, Garwood J. Bone response to termination of oestrogen treatment. Lancet $1978 ; \mathrm{i}: 1325-7$.

13 Quint BC. Changing patterns in endometrial adenocarcinoma. Am J Obstet Gynecol 1975;122:498-501.

14 Smith DC, Prentice R, Thompson DJ, Herman WL. Association of exogenous estrogen and endometrial carcinoma. N Engl J Med 1975;293:1164.

15 Zeil HK, Finkle WD. Increased risk of endometrial carcinoma among users of conjugated estrogens. $N$ Engl J Med 1975;293:1167.

16 Hammond CB, Jelovsek FR, Lee KL, Creasman WT, Parker RT. Effects of long-term estrogen replacement therapy. Am J Obstet Gynecol 1979;133:525-36.

17 Christiansen C, Rodbro P. Long-term reproducibility of bone mineral content measurements. Scand J Clin Lab Invest $1977 ; 37: 321-3$.

18 Knowelden J, Buhr AJ, Dunbar O. Incidence of fractures in persons over 35 years of age. Br J Prev Soc Med $1964 ; 18: 130-41$.

Requests for reprints to Dr M A Smith, Department of Medical Physics and Medical Engineering, Royal Infirmary, Lauriston Place, Edinburgh EH3 9YW. 